Drug retention was higher for bDMARD naïve compared with non-naïve patients (figure 1a). Baseline characteristics and disease activity (data not shown) as well as drug retention differed in-between the European registries (figure 1b).

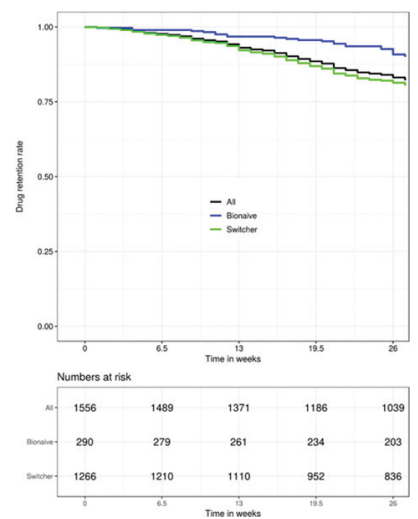

Figure 1a. Pooled 6-month secukinumab retention rates for axSpA patients in EuroSpA, as well as compared between the bDMARD naïve and non-naïve patients (log rank test; $\mathrm{p}<0.001)$.
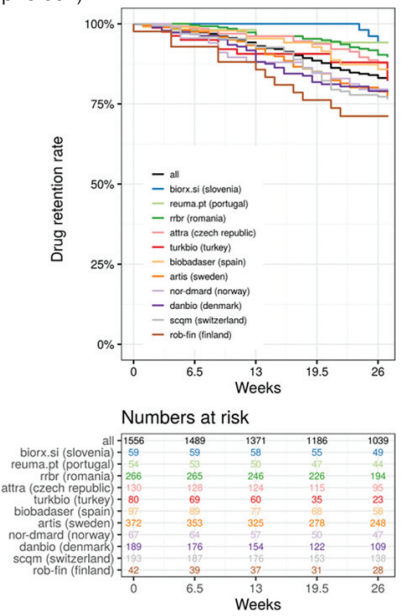

Figure 1b. Pooled 6-month secukinumab retention rate as well as compared across 11 registries in EuroSpA (log rank test; $p<0.001$ ). ICEBIO was excluded from the Kaplan-Meier plot (<10 patients).

Conclusion: This study of $>1500$ patients in 12 European countries provides real-world data on the effectiveness of secukinumab in patients with axSpA, adding evidence to existing RCTs. A majority of the patients was previous bDMARD users and had long disease duration. BASDAI $<4$ was achieved by $49 \%$ of the patients and ASDAS $<1.3$ by $9 \%$ at 6 months. Overall retention rate was $83 \%$ at 6 months, with significant differences across the registries and higher retention rates for bDMARD naïve compared with non-naïve axSpA patients.

Acknowledgement: Novartis Pharma AG and IQVIA for supporting the EuroSpA collaboration

Disclosure of Interests: Brigitte Michelsen Grant/research support from: Unrestricted grant: Novartis, Consultant for: Novartis, UCB, Cecilie Heegaard Brahe Grant/research support from: Unrestricted grant: Novartis, Johan Askling Grant/research support from: Karolinska Institutet (JA) has or has had research agreements with the following pharmaceutical companies, mainly in the context of the ATRIS national safety monitoring programme for rheumatology biologicals: Abbvie, BMS, MSD, Eli Lilly, Pfizer, Roche, Samsung Bioepis, and UCB., Consultant for: Karolinska Institutet has received remuneration for JA participating in ad boards arranged by Lilly, Novartis, and Pfizer., Catalin Codreanu: None declared, Adrian Ciurea Consultant for: AbbVie, Celgene, Janssen-Cilag, MSD, Eli Lilly, Novartis, Pfizer, UCB, Speakers bureau: Abbvie, Celgene, Janssen-Cilag, MSD, Eli Lilly, Novartis, Pfizer, UCB, Anne Gitte Loft: None declared, Heřman Mann Consultant for: Pfizer, Eli Lilly, Sanofi, Speakers bureau: AbbVie, Roche, Pfizer, MSD, Eli Lilly, Sanofi, Manuel Pombo-Suarez: None declared, Fatos Onen: None declared, Joe Sexton: None declared, Ziga Rotar: None declared, Maria Jose Santos: None declared, Kari Eklund: None declared, Björn Gudbjornsson: None declared, Florenzo lannone Consultant for: $F$ lannone has received consultancy fees and/or speaker honoraria from Pfizer, AbbVie, MSD, BMS, Novartis, Lilly, UCB outside this work, Speakers bureau: $F$ lannone has received consultancy fees and/or speaker honoraria from Pfizer, AbbVie, MSD, BMS, Novartis, Lilly, UCB outside this work, Daniela Di Giuseppe: None declared, Rux andra lonescu: None declared, Michael Nissen Consultant for: AbbVie, Lilly, Novartis, and Pfizer, Karel Pavelka: None declared, Carlos SánchezPiedra: None declared, Servet Akar Grant/research support from: MSD, Abbvie, Roche, UCB, Novartis, Pfizer, Amgen, Consultant for: MSD, Abbvie, Roche, UCB, Novartis, Pfizer, Amgen, Speakers bureau: Pfizer, Eirik kristianslund: None declared, Matija Tomsic: None declared, Helena Santos: None declared, Nina Trokovic: None declared, Arni Jon Geirsson: None declared, Ennio Giulio Favalli: None declared, Irene van der HorstBruinsma Grant/research support from: MSD, Pfizer, AbbVie, Consultant for: Abbvie, UCB, MSD, Novartis, Speakers bureau: BMS, AbbVie, Pfizer, MSD, Gary Macfarlane Grant/research support from: Have received research grants (not current) from Abbvie and Pfizer.

Have received research grants (not current) from the British Society for Rheumatology, who received the funds from Abbive, Pfizer and UCB. Have received research grant (current) from the British Society for Rheumatology, who received the funds from Celgene., Lise Hyldstrup: None declared, Niels Steen Krogh: None declared, Mikkel Ǿstergaard Grant/ research support from: Abbvie, Celgene, Centocor, Merck, Novartis, Consultant for: Abbvie, BMS, Boehringer-Ingelheim, Celgene, Eli Lilly, Hospira, Janssen, Merck, Novartis, Novo, Orion, Pfizer, Regeneron, Roche, and UCB, Speakers bureau: Abbvie, BMS, Boehringer-Ingelheim, Celgene, Eli Lilly, Hospira, Janssen, Merck, Novartis, Novo, Orion, Pfizer, Regeneron, Roche, and UCB, Merete L. Hetland Grant/research support from: BMS MSD, AbbVie, Roche, Novartis, Biogen, Pfizer, Consultant for: Eli Lilly, Speakers bureau: Orion Pharma, Biogen, Pfizer, CellTrion, Merck, Samsung Bioepis DOI: 10.1136/annrheumdis-2019-eular.1601

\section{FRI0405 AQUILA STUDY IN GERMANY - REAL WORLD DATA ON SECUKINUMAB'S EFFECTIVENESS IN PSORIATIC ARTHRITIS PATIENTS - RESULTS FROM AN INTERIM ANALYSIS}

Uta Kiltz ${ }^{1}$, Daniel Peterlik ${ }^{2}$, Veronika Winkelmann ${ }^{2}$, Hans-Peter Tony ${ }^{3}$, on behalf of the AQUILA Study Group. ${ }^{1}$ Rheumazentrum Ruhrgebiet, Herne, and Ruhr University, Bochum, Germany; ${ }^{2}$ Novartis Pharma GmbH, Clinical Research Immunology, Hepatology and Dermatology, Nürnberg, Germany; ${ }^{3}$ Medizinische Klinik II, Universitätsklinik, Rheumatology/Immunology, Würzburg, Germany

Background: Psoriatic arthritis (PsA) is a chronic, progressive, inflammatory disorder of skin and joints, it impacts both physical and emotional well-being, and increases the risk of comorbidities. Thus, improvement of disease activity as well as emotional well-being is of utmost importance in treatment of PsA patients (pts). In clinical trials, secukinumab, an antiinterleukin (IL)-17A monoclonal antibody, has shown to significantly improve signs and symptoms of $\mathrm{PsA}^{1}$.

Objectives: To evaluate real-world interim data on the effectiveness of secukinumab on treatment outcomes and quality of life (QoL) in pts with active PSA.

Methods: AQUILA is an ongoing, 52-week (wk) non-interventional study enrolling 2000 pts with active PsA and ankylosing spondylitis. Here, we report interim results of effectiveness in a subgroup of PsA pts treated with secukinumab.

Validated questionnaires were used to measure effectiveness of secukinumab on:

- disease activity

- Physician's Global Assessment (PhGA, 0=no disease activity, 10=most intense disease activity),

- Psoriasis Area and Severity Index (PASI),

- American College of Rheumatology (ACR) joint count and

- C-reactive protein (CRP);

- $\quad$ and QoL

- Psoriatic Arthritis Impact of Disease 12-item score (PsAID-12),

- Medical Outcomes Study (MOS) Sleep scale and

- Beck's Depression Inventory II (BDI-II).

Pts who were already under secukinumab treatment or just about initiating secukinumab therapy, based on medical therapeutic need, were included; in both scenarios, disease activity at start of secukinumab treatment was used as starting point for analysis. Treatment decision was made independently of participating in this study. Pts were observed from 
BL up to wk 52 according to clinical routine. Real-world effectiveness of secukinumab was assessed prospectively and analyzed as observed.

Results: At BL, 641 PsA pts were included of whom 385 (60.1\%) completed 52 wks so far (i.e. at the time of data cut-off for this interim analysis). $58.5 \% \quad(n=375)$ of the pts were female and $41.5 \% \quad(n=266)$ were male, mean age was 52.6 years. About $66 \% \quad(n=424)$ were pre-treated with biologics. Mean PhGA improved from 5.3 at $B L(n=571,89.1 \%)$ to 2.5 at wk $52(n=341,53.2 \%)$. Mean absolute PASI improved from 8.1 at BL $(n=211,32.9 \%)$ to 1.2 at wk $52(n=147,22.9 \%)$. More than half of the documented pts (51 out of 94 ) achieved a $100 \%$ reduction (PASI 100 ) in skin symptoms at wk 52. The mean number of tender/swollen joints (ACR) was reduced from $7.6(n=436,68.0 \%) / 3.9(n=437,68.2 \%)$ to $3.0(n=241,37.6 \%) / 0.7(n=242,37.8 \%)$ at wk 52. The percentage of pts with CRP $>5 \mathrm{mg} / \mathrm{L}$ dropped from $43.0 \%$ at BL $(n=230)$ to $36.6 \%$ at $w \mathrm{k}$ $52(n=112)$. Mean PsAID-12 improved from 5.0 at $B L(n=602,93.9 \%)$ to 3.3 at wk $52(n=343,53.5 \%)$. The percentage of PsA pts with high disease activity (score $\geq 5$ ) assessed by PsAID-12 dropped from $61.0 \%$ at BL $(n=367)$ to $26.2 \%$ at wk $52 \quad(n=90)$. MOS sleep scales did not change relevantly over time. With respect to pts with a BDI-II reduction of at least 3 score points, the mean value improved from 16.4 (mild depression) at $B L$ to 8.0 (no depression) at wk 52 ( $n=123,19.2 \%$ ). Conclusion: Secukinumab reduced disease activity and improved QoL already within this subgroup of PsA pts. Thus, real-world data from the AQUILA study show that, in clinical routine, secukinumab treatment up to one year provides a clear benefit for PsA pts in clinical and QoL parameters.

\section{REFERENCES:}

[1] Mease PJ, et al. N Engl J Med. 2015;373:1329-39

Disclosure of Interests: Uta Kiltz Grant/research support from: AbbVie, Chugai, Eli Lilly, Grünenthal, Janssen, MSD, Novartis, Pfizer, Roche, and UCB., Consultant for: AbbVie, Chugai, Eli Lilly, Grünenthal, Janssen, MSD, Novartis, Pfizer, Roche, and UCB., Daniel Peterlik Employee of: Novartis Pharma $\mathrm{GmbH}$, Veronika Winkelmann Employee of: Novartis Pharma GmbH, Hans-Peter Tony Consultant for: Eli Lilly and Company, Speakers bureau: Eli Lilly and Company DOI: 10.1136/annrheumdis-2019-eular.436

\section{FRI0406 AQUILA STUDY IN GERMANY - REAL WORLD DATA ON SECUKINUMAB'S EFFECTIVENESS IN ANKYLOSING SPONDYLITIS PATIENTS - RESULTS FROM AN INTERIM ANALYSIS}

Uta Kiltz ${ }^{1}$, Daniel Peterlik ${ }^{2}$, Veronika Winkelmann ${ }^{2}$, Hans-Peter Tony ${ }^{3}$, on behalf of the AQUILA Study Group. ${ }^{1}$ Rheumazentrum Ruhrgebiet, Herne, and Ruhr University, Bochum, Germany; ${ }^{2}$ Novartis Pharma GmbH, Clinical Research Immunology, Hepatology and Dermatology, Nürnberg, Germany; ${ }^{3}$ Medizinische Klinik II, Universitätsklinik, Rheumatology/Immunology, Würzburg, Germany

Background: Ankylosing spondylitis (AS) is characterized by chronic inflammation of the spine and is at high risk to cause inflammation, pain, and stiffness extraspinal as well. Thus, important aims in therapy of AS are pain reduction and maintenance of physical functioning. Secukinumab, a fully human monoclonal antibody that selectively neutralizes interleukin (IL)-17A, has already shown significant efficacy in the treatment of AS in clinical trails ${ }^{1}$.

Objectives: The aim of this interim analysis is to evaluate the effectiveness of secukinumab on disease activity, physical functioning and quality of life in AS patients (pts) in a real world setting.

Methods: AQUILA is an ongoing, multi-center, 52-week (wk) non-interventional study enrolling 2000 pts with active AS and psoriatic arthritis in Germany. Here, we report interim results of effectiveness in a subgroup of AS pts treated with secukinumab.

Validated questionnaires were used to measure the effectiveness of secukinumab on:

- disease activity

- o Physician's Global Assessment (PhGA: 0=no disease activity, 10=most intense disease activity),

- o Bath Ankylosing Disease Activity Index (BASDAI),

- o C-reactive protein (CRP)

- physical functioning

- o global functioning: Assessment of Spondyloarthritis Health Index, (ASAS$\mathrm{HI}$ ),

- $\quad$ and key aspects of sleep

- o Medical outcomes Study Sleep Scale (MOS),
- severity of depression

o Beck's Depression Inventory Version II (BDI-II)

Pts who were already under secukinumab treatment or just about initiat ing secukinumab therapy, based on medical therapeutic need, were included; in both scenarios, disease activity at start of secukinumab treatment was used as starting point for analysis. Treatment decision was made independently of participating in this study. Pts were observed from BL up to wk 52 according to clinical routine. Real-world effectiveness of secukinumab was assessed prospectively and analyzed as observed.

Results: This interim analysis describes 311 AS pts who were included at $\mathrm{BL}$ and of whom $178(57.2 \%)$ have completed wk 52 so far (i.e. at the time of data cut-off for this interim analysis). $63.3 \% \quad(n=197)$ of the pts were male and $36.7 \% \quad(n=114)$ female, mean age was 47 years About $70 \% \quad(n=221)$ of the pts were pre-treated with biologics. Physicians reported a mean PhGA value of 5.9 at $B L(n=282,90.7 \%)$ which improved to 2.6 at wk $52(n=168,54.0 \%)$. Mean BASDAI value was reduced from 5.6 at $B L(n=301,96.8 \%)$ to 4.0 at wk $52(n=171,55.0 \%)$ With regard to inflammation parameters, the percentage of pts with a CRP of $>5 \mathrm{mg} / \mathrm{L}$ decreased from $54.7 \% \quad(n=140)$ to $40.0 \% \quad(n=58)$ at $w k$ 52. Further, mean ASAS-HI value decreased over time from 8.2 at BL $(n=274,88.1 \%)$ to 6.3 at wk $52(n=156,50.2 \%)$. MOS sleep scale did not change over time, yet only few BL documentations for these scales were available (range $\mathrm{n}=26$ to 44). Regarding depressive mood of the pts, while at BL $40.7 \%(n=101)$ of the pts suffered from mild to severe depression (BDI-II score between 14 and 63), 30.3\% ( $n=46)$ did so in wk 52. This is reflected by a drop of mean BDI-II value from 13.0 at BL $(n=248,79.7 \%)$ to 10.6 at wk $52(n=152,48.9 \%)$.

Conclusion: Within this limited subset of AS pts, secukinumab reduced disease activity and improved quality of life for up to one year as assessed by validated physicians' as well as pt-reported outcomes. Overall, this interim analysis gives promising insights into treatment effects of secukinumab on pts' physical and mental well-being under real-world conditions.

\section{REFERENCES:}

[1] Baeten D, et al. N Engl J Med. 2015;373:2534-4

Disclosure of Interests: Uta Kiltz Grant/research support from: AbbVie, Chugai, Eli Lilly, Grünenthal, Janssen, MSD, Novartis, Pfizer, Roche, and UCB., Consultant for: AbbVie, Chugai, Eli Lilly, Grünenthal, Janssen, MSD, Novartis, Pfizer, Roche, and UCB., Daniel Peterlik Employee of Novartis Pharma GmbH, Veronika Winkelmann Employee of: Novartis Pharma GmbH, Hans-Peter Tony Consultant for: Eli Lilly and Company Speakers bureau: Eli Lilly and Company DOI: 10.1136/annrheumdis-2019-eular.437

\section{FRI0407 \\ TWO-YEAR ULTRASOUND CONTROLLED STUDY OF HYALINE CARTILAGE AND SYNOVIAL LAYER STRUCTURE OF HIP JOINTS IN PATIENTS WITH ANKYLOSING SPONDYLITIS DURING TREATMENT WITH ADALIMUMAB}

Andriy Petrov ${ }^{1}$, Anife Gaffarova ${ }^{1}$, Aleksey Petrov ${ }^{1}$, Jana Shevnina ${ }^{2} .{ }^{1}$ Crimean Federal University. Medical Academy, Simferopol, Russian Federation; ${ }^{2}$ Crimean Clinical Hospital n.a. N.A. Semashko, Simferopol, Russian Federation

Background: The impairment of hip joints has significant prognostic value on functional status of patients with Ankylosing spondylitis (AS) [1]. One of possible yearly marker of hip joints structure damage in patients with AS may be changing in volume of hyaline cartilage [2]. Objectives.

Objectives: To investigate changes in width of hyaline cartilage and synovial layer of hip joints in patients with coxitis, associated with AS under treatment with adalimumab (ADA) during 2 years.

Methods: The 28 patients with AS and clinical, ultrasound and radiographic signs of coxitis (21 male, 7 female, average age is 35.4 years old, duration of disease is 12-132 month) were included into study. All patients were being treated by NSAIDs at least 3 months before they started to take ADA (40 mg subcutaneously every 2 weeks). Treatment with ADA was continued during 24 months. Patients were observed at month 0,12 and 24 months of treatment including measurements of pain visual analog scale (VAS) in hip movements, maximal distance between ankles, pelvic X-ray and sonography of hip joints by $10-18 \mathrm{MHz}$ probe. BASRI-Hips index was applied for radiographic estimation of structura damage of hip joints [3]. During sonography width of hip joint capsule and hyaline cartilage were measured. The Mann-Whitney- $U$ test was used for comparison of changes in clinical and sonographic data between two groups of patients. 